Plant Tissue Cult. \& Biotech. 30(2): 267-275, 2020 (December)

(CBangladesh Assoc. for Plant Tissue Culture \& Biotechnology

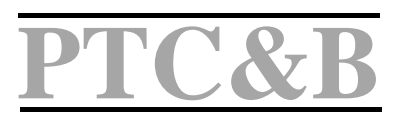

\title{
Micropropagation of Two Varieties of Bell pepper (Capsicum annuum L.)
}

\author{
Shilpi Akther', Tanjina Akhtar Banu, Salim Khan, Shahina Akter, \\ Ahashan Habib, Mousona Islam, Barna Goswami \\ and Bivas Kumar Sarkar ${ }^{1 *}$ \\ Plant Tissue Culture Section, BCSIR Laboratories, Dhanmondi, Dhaka-1205, Bangladesh \\ Key words: Micropopagation, Capsicum annuum, Cotyledonary leaf
}

\begin{abstract}
Cotyledonary leaf and node of two varieties, namely red and yellow of Bell pepper (Capsicum annuum L.) were cultured in MS with different concentrations and combinations of plant growth regulators. The cotyledonary leaf was found to be most responsive towards multiple shoot regeneration. The leaf explants of red variety showed best result towards shoot regeneration in MS with BAP $(8.0 \mathrm{mg} \Lambda)$, NAA $(0.02 \mathrm{mg} /)$ and IAA $(1.0 \mathrm{mg} \Lambda)$. Eighty per cent explants responded within 13 - 14 days, and the mean number of shoot per explant was was found to be 5.67. The cotyledonary leaf explants of yellow variety showed promising result when the cotyledonary leaf explant was cultured in MS with BAP $(8.0 \mathrm{mg} \Lambda)$ and NAA $(0.5 \mathrm{mg} \Lambda)$ being the mean number of shoot per explants 5.13 and $70 \%$ of them responded within 14 - 15 days. Maximum root induction was found in MS with IBA $(0.5 \mathrm{mg} \Lambda)$ in both capsicum varieties. After successful root formation plantlets were transplanted and acclimatized to the soil.
\end{abstract}

\section{Introduction}

Capsicum annuum is a herbaceous flowering plant and belongs to Solanaceae. The genus Capsicum contains about 20 species. Of them, five are recognized widely (Sanatombi and Sharma 2007). C. annuum is one of the most important vegetable crops globally and commonly known as pepper, sweet pepper or bell pepper. Different colored bell peppers, namely red, green, yellow, brown, purple, etc. are available as indispensible vegetable kitchen item as well as in other form condiment and spice, adding colour, flavor, zest, and piquancy various foodstuffs. It is an excellent source of vitamins A, B-complex, C, E, and is rich in minerals like molybdenum, manganese, phosphorus, and potassium (Saleh et al. 2018).

*Author for correspondence: 〈bs25us@yahoo.com>. 1Department of Botany, Jagannath University, Dhaka-1100, Bangladesh.

DOI: https://doi.org/10.3329/ptcb.v30i2.50696 
Capsicum is an essential summer crop of temperate regions, but nowadays, the effort is being made to grow sweet pepper in Bangladesh (Mahmud et al. 2017). It has great demand all over the country. Some advanced farmers grow capsicum sporadically to meet the need of the periphery of cities (Saha and Salam 2004) which is not enough to meet the increasing demand. Moreover, pepper seeds characteristically have short viability and rapidly lose germination capacity. The crop is susceptible to environmental factors, and its yield is affected significantly (Halim and Islam 2013). Micropropagation is a unique tool that is very convenient for maintaining the genetic homogeneity of the elite plant materials and preserving heterozygous genotypes and genetically transformed forms (Dabauza and Pena 2001). The genus Capsicum is recalcitrant regarding its in vitro regeneration potential, which makes it difficult or efficient to apply recombinant DNA technologies via genetic transformation aimed at genetic improvement against pests and disease (Ashrafuzzaman et al. 2009). A number of studies have been carried out on the regeneration of bell pepper globally and in Bangladesh. A number of experiments were followed to demonstrate the effectiveness of plant micropropagation in different species of pepper (Capsicum spp.) varies depending on the plant genotype, the type of initial explants, and the factors and conditions of in vitro cultures (Dabauza and Pena 2001). Multiple shoot induction and plant regeneration from nodal explants of $C$. annuum were reported by Kumar et al. (2011), Hegde et al. (2017).

To overcome the major constraints of recalcitrant response of bell pepper (C. annuum), the present investigation was carried out. This work presents an efficient and reproducible in vitro regeneration protocol for two varieties, namely red and yellow bell pepper in Bangladesh.

\section{Materials and Methods}

The seeds of both red and yellow varieties of bell peppers were collected from the local market, and used for germinating plantlets which were further used as explants. The cotyledonary leaf and node were used as explants. The same sterilization procedures described by Khan et al. (2018) was followed. This work was conducted in the Tissue Culture Section, Biological Research Division of Bangladesh Council of Scientific and Industrial Research (BCSIR), Dhaka.

Preparation of the explants from in vitro growing seedling was carried out. Different concentrations and combinations of plant growth regulators (PGRs) such as BAP, IAA, NAA and $\mathrm{Kn}$ were used in MS to develop multiple shoots. For induction and development of root, about $3-4 \mathrm{~cm}$ long shoots were separated and cultured on freshly prepared full and half strength of MS with different concentrations $(0.25-1.0 \mathrm{mg} /)$ of IBA. All media contained 3\% sucrose and $0.8 \%$ agar or gel rite with $5.8 \mathrm{pH}$ adjusted before autoclaving. All cultures were maintained in $16 \mathrm{hrs}$ photoperiod at $25 \pm 2^{\circ} \mathrm{C}$.

The plantlets with sufficiently developed roots were taken out from the culture vessels, and the roots were washed under running tap water. The plantlets were then 
transplanted to small pots containing sterilized soil. Three weeks after transplantation, when the regenerated plants were fully established in the small pots, they were transferred to larger pots for further growth and development.

\section{Result and Discussion}

The plant growth regulators, namely auxin and cytokinin are critical for plant regeneration in tissue culture (Hill and Schaller 2013). Usually, high cytokine in to auxin ratio is beneficial for shoot regeneration (Phillips and Hubstenberger 1985). Therefore, the influence of various concentrations of cytokinin (BAP) alone or with auxin (IAA or NAA) in MS was studied on shoot induction and their development in bell pepper. The fundamental goal of in vitro culture of bell pepper was to develop a reliable protocol for achieving plant regeneration from both varieties using explants cotyledonary leaf and cotyledonary node. Bhutia et al. (2016) observed that among the explants (hypocotyl, cotyledon, nodal, and shoot tip), shoot tip and cotyledon explants performed the best of shooting frequency and shoot number. Similar observations were also reported in five varieties of Capsicum (Sawmy et al. 2014). In this study, the best response was observed from the cotyledonary leaf explants of both types (Tables 1 and 2).

Table 1. Responses of explants towards shoot regeneration on MS with different combinations of BAP, NAA and IAA on red variety of $C$. annuum.

\begin{tabular}{|c|c|c|c|c|c|c|c|}
\hline \multirow[t]{2}{*}{$\begin{array}{l}\text { Name of } \\
\text { explants }\end{array}$} & \multicolumn{3}{|c|}{$\begin{array}{c}\text { PGRs } \\
\text { supplements }(\mathrm{mg} \Lambda)\end{array}$} & \multirow{2}{*}{$\begin{array}{c}\text { No. of } \\
\text { explants } \\
\text { inoculated }\end{array}$} & \multirow{2}{*}{$\begin{array}{l}\% \text { of } \\
\text { responsive } \\
\text { explants }\end{array}$} & \multirow{2}{*}{$\begin{array}{l}\text { Days to } \\
\text { shoot } \\
\text { initiation }\end{array}$} & \multirow{2}{*}{$\begin{array}{c}\text { Mean no. of } \\
\text { shoot /explants } \\
\text { after } 3 \text { months) }\end{array}$} \\
\hline & BAP & NAA & IAA & & & & \\
\hline \multirow[t]{6}{*}{$\mathrm{CL}$} & 4.0 & 0.02 & 0.5 & 20 & 60 & $16-18$ & 3.93 \\
\hline & 4.0 & 0.02 & 1.0 & 20 & 65 & $19-20$ & 3.47 \\
\hline & 6.0 & 0.02 & 0.5 & 20 & 60 & $20-21$ & 4.60 \\
\hline & 6.0 & 0.02 & 1.0 & 20 & 70 & $20-21$ & 4.93 \\
\hline & 8.0 & 0.02 & 0.5 & 20 & 75 & $12-13$ & 5.33 \\
\hline & 8.0 & 0.02 & 1.0 & 20 & 80 & $11-12$ & 5.67 \\
\hline \multirow[t]{6}{*}{$\mathrm{CN}$} & 4.0 & 0.02 & 0.5 & 20 & 60 & $17-18$ & 1.47 \\
\hline & 4.0 & 0.02 & 1.0 & 20 & 60 & $16-18$ & 1.93 \\
\hline & 6.0 & 0.02 & 0.5 & 20 & 70 & $20-21$ & 1.73 \\
\hline & 6.0 & 0.02 & 1.0 & 20 & 65 & $20-21$ & 2.26 \\
\hline & 8.0 & 0.02 & 0.5 & 20 & 60 & $12-13$ & 2.67 \\
\hline & 8.0 & 0.02 & 1.0 & 20 & 75 & $12-13$ & 3.06 \\
\hline
\end{tabular}

$\mathrm{CL}=$ Cotyledonary leaf, $\mathrm{CN}$ = Cotyledonary node.

Different concentrations of BAP, IAA and NAA were used in MS to determine the optimum media composition for the initiation and development of multiple shoots from both explants of the red variety. The results of the experiments are shown in Table 1. MS containing $8.0 \mathrm{mg} / \mathrm{BAP}, 0.02 \mathrm{mg} / \mathrm{NAA}$, and $1.0 \mathrm{mg} / \mathrm{IAA}$ exhibited the best response 
towards shoot initiation and their multiplication from both the explants (Table 1). The best response was recorded from cotyledonary leaf where direct shoot induction started within 11 - 12 days from the base of leaf explants (Fig. 1a) followed by shoot bud
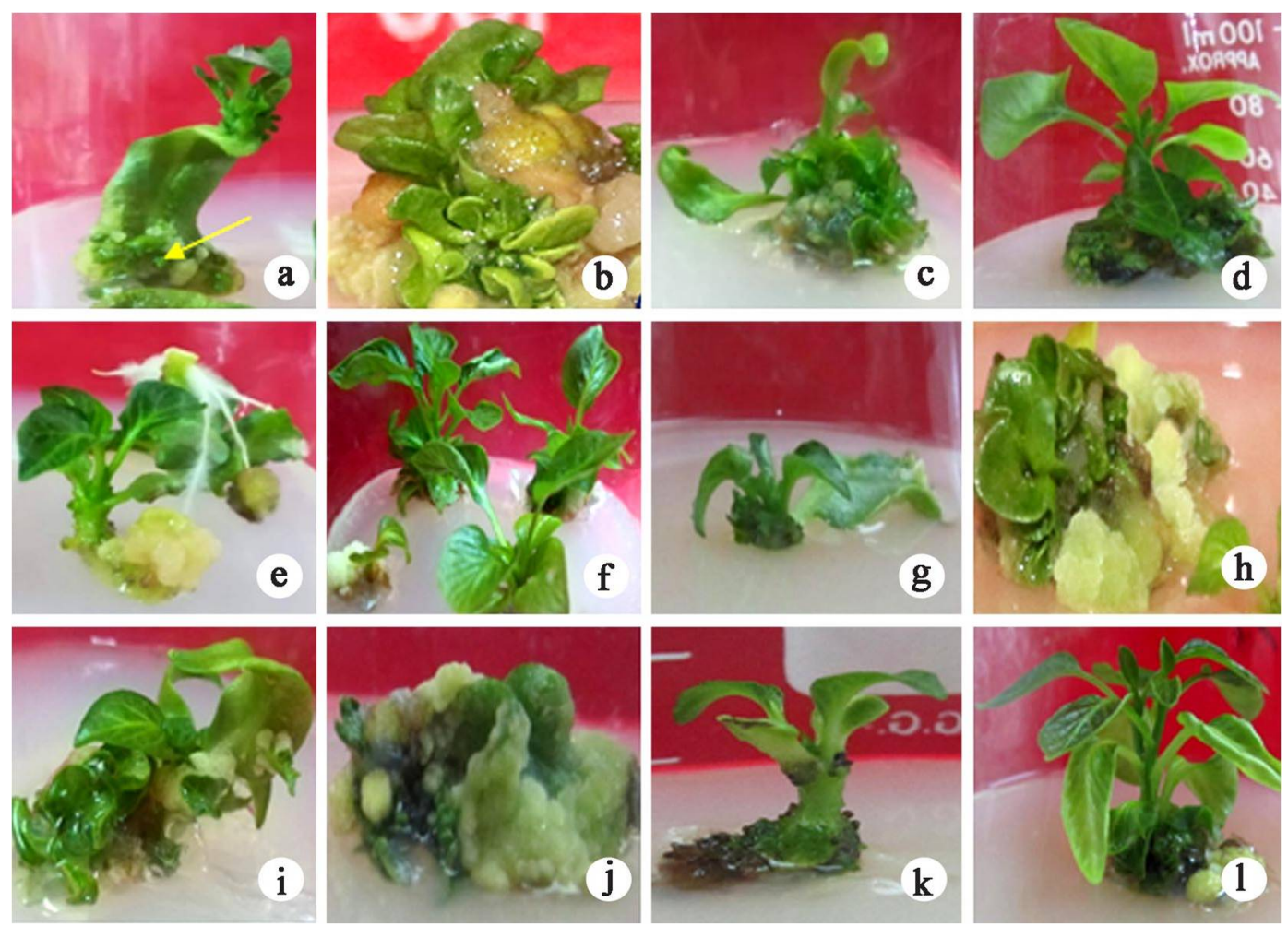

Fig. 1. Different stages of regeneration from cotyledonary leaf and nodal explants of both red and yellow variety of $C$. annuum. (a) Initiation of direct shoots from cotyledonary leaf of red variety. (b) Formation of sessile leaves from leaf explant on same media combination and variety as in Fig. a. (c) Proliferation of a few shoots from leaf explants. (d) Elongated shoots on MS with $0.5 \mathrm{mg} /$ IAA. (e) Shoot regeneration from nodal explants of red variety on the same media combination as mention in Fig. a. (f) Elongated shoots from nodal explants of red variety. (g) Initiation of shoots from the base of leaf explants of yellow variety. (h) Formation of leaves from leaf explant on same media combination and variety as in Fig. g; (i) Multiple shoots on MS with $0.5 \mathrm{mg} /$ IAA. (j) Formation of callus rather than shoot induction ion on same media as in Fig. g. (k) Formation of shoot from nodal explant of yellow variety on same media as in Fig. g. (1) Elongated shoots from nodal explants of yellow variety.

induction and shoot regeneration. It required 10 - 12 weeks to grow fully mature shoots. Sometimes callus was produced from the cut end of the leaf, but the callus did not show any sign towards shoot formation (Fig. 1a). Similar observations were also made in Capsicum spp. by Venkatian et al. 2001 indicating that the leaf explant was more amenable to the regeneration of adventitious shoots than the other explants. 
Table 2. Responses of explants towards shoot regeneration on MS with different combinations of BAP and NAA on yellow variety of $C$. annuum.

\begin{tabular}{lcccccc}
\hline $\begin{array}{l}\text { Name of } \\
\text { explants }\end{array}$ & \multicolumn{2}{c}{ PGRs (mg 1$)$} & $\begin{array}{c}\text { No. of } \\
\text { explants } \\
\text { inoculated }\end{array}$ & $\begin{array}{c}\text { \% of } \\
\text { responsive } \\
\text { explants }\end{array}$ & $\begin{array}{c}\text { Days to } \\
\text { shoot } \\
\text { initiation }\end{array}$ & $\begin{array}{c}\text { Mean no. of shoot / } \\
\text { explants (after 3 } \\
\text { months) }\end{array}$ \\
\hline CL & 4.0 & 0.5 & 20 & 20 & $16-17$ & 3.20 \\
& 4.0 & 1.0 & 20 & 15 & $16-18$ & 3.66 \\
& 6.0 & 0.5 & 20 & 15 & $17-16$ & 3.93 \\
& 6.0 & 1.0 & 20 & 25 & $17-16$ & 4.33 \\
& $\mathbf{8 . 0}$ & $\mathbf{0 . 5}$ & $\mathbf{2 0}$ & $\mathbf{7 0}$ & $\mathbf{1 5 - 1 6}$ & $\mathbf{5 . 1 3}$ \\
& 8.0 & 1.0 & 20 & 55 & $15-16$ & 4.80 \\
& 4.0 & 0.5 & 20 & 20 & $16-17$ & 1.27 \\
& 4.0 & 1.0 & 20 & 15 & $16-17$ & 1.40 \\
& 6.0 & 0.5 & 20 & 10 & $17-16$ & 1.80 \\
& 6.0 & 1.0 & 20 & 15 & $17-16$ & 2.33 \\
& 8.0 & 0.5 & 20 & 55 & $15-16$ & 2.40 \\
& $\mathbf{8 . 0}$ & $\mathbf{1 . 0}$ & $\mathbf{2 0}$ & $\mathbf{6 0}$ & $\mathbf{1 4 - 1 5}$ & $\mathbf{2 . 6 7}$ \\
\hline
\end{tabular}

$\mathrm{CL}=$ Cotyledonary Leaf, $\mathrm{CN}=$ Cotyledonary Node.

In combination of BAP, NAA and IAA cotyledonary leaf explants of red variety showed $80 \%$ shoot initiation with maximum (5.67) mean number of shoots as against 3.06 in node explants (Table 1). Borychowski et al. (2002), Ashrafuzzaman et al. (2009) observed the highest number of shoot regeneration on MS in the combination with 5.0 $\mathrm{mg} / \mathrm{BAP}$ with $1.0 \mathrm{mg} / \mathrm{IAA}$ from cotyledon and hypocotyl explants, respectively.

However, Raj et al. (2015) and Kumar et al. (2011) found best result by using MS with BAP $(5 \mathrm{mg} \Lambda)$ and IAA $(0.1 \mathrm{mg} \Lambda)$ from leaf and cotyledons explants, respectively. In the present experiment, calli were found to develop from the leaf explants. Only adventitious leaves were often formed from the explants that were not appropriately elongated (Fig. 1b). Orlinska and Nowaczyk (2014) found the formation of clusters of sessile leaves during organogenesis induction. Very often, only a few shoots were elongated even if enough multiple shoots were formed (Fig. 1c). For proper elongation $\mathrm{GA}_{3}$ was added in the subcultured of multiple explants, but no significant elongation was observed. But, when the multiple shoots were subcultured on MS with $0.5 \mathrm{mg} / \mathrm{IAA}$ better elongation was observed compared to regular media combinations of BAP, NAA, and IAA (Fig. 1d). On the other hand, MS with BAP (8.0 mg $/)$, NAA (0.02 mg $/$ ) and IAA $(1.0 \mathrm{mg} /)$ also showed the best response in cotyledonary node explants. In node explants of red variety lower number of shoots was found to form than leaf explants. Seventy five per cent of explants responded towards regeneration within 13 - 14 days (Fig. 1e), and the 
mean number of shoot per explants was 3.06 (Fig. 1f). Ashrafuzzaman et al. (2009) found the highest number of shoots from cotyledon in MS with BAP ( $5.0 \mathrm{mg} /$ ) and IAA (1.0 $\mathrm{mg} /$ ).

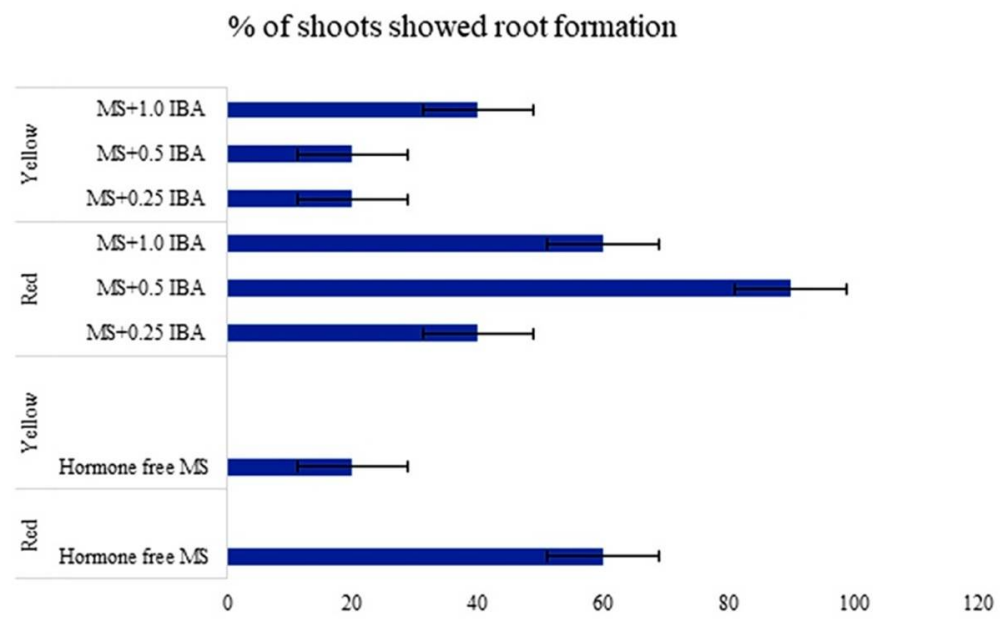

Fig. 2. Effect of the different media and PGR (IBA) conditions on root induction

from the in vitro regenerated shoots of red and yellow variety of C. annuum.

In yellow variety of bell pepper, among the various combinations of BAP (4.0 - 8.0 $\mathrm{mg} \Lambda)$ and NAA (0.5 - $1.0 \mathrm{mg} \Lambda)$ cotyledonary leaf explants showed better response than cotyledonary node (Table 2). Song et al. (2010) also got the best result from leaf explants of the "Hivita Yellow" variety of Capsicum. In this experiment, the most promising results towards the shoot regeneration were recorded from cotyledonary leaf explants when they were cultured in MS supplemented with BAP $(8.0 \mathrm{mg} /)$ and NAA $(0.5 \mathrm{mg} /)$. In this combination of BAP and NAA 70\% explants responded towards shoot initiation within 14 - 15 days (Fig. 1g) and the mean number of shoots per explants was recorded 5.13 within three months of culture. Like the red variety leaf explants produced huge number of sessile leaf rather than uniform shoots (Fig. 1h). The multiple shoots were subcultured in MS with IAA $(0.5 \mathrm{mg} \Lambda)$ for their elongation. On IAA (0.5 mg $\Lambda$ ) supplemented media, moderate elongation was observed (Fig. 1i). Occasionally huge callus was formed from the leaf explants of yellow variety (Fig. 1j). But from the callus, no shoots were found to regenerate. Song et al. (2010) reported that the highest number (5.6) of regenerated shoot buds was obtained when leaf explants were cultured on an MS with TDZ $(2.0 \mathrm{mg} /)$ and NAA $(0.1 \mathrm{mg} / \mathrm{N})$ in 'Hivita Yellow' variety. The combination of BAP $(8.0 \mathrm{mg} \Lambda)$ and NAA $0.5 \mathrm{mg} \Lambda)$ on MS cotyledonary node also exhibited better response than all other combinations (Table 2). By using the cotyledonary node, as explants $60 \%$ of explants showed shoot initiation (Fig. 1k). Cotyledonary node explants 
produced a comparatively lower mean number (2.67) of shoots than leaf explants. Generally, no callus was found to have formed from cotyledonary node.
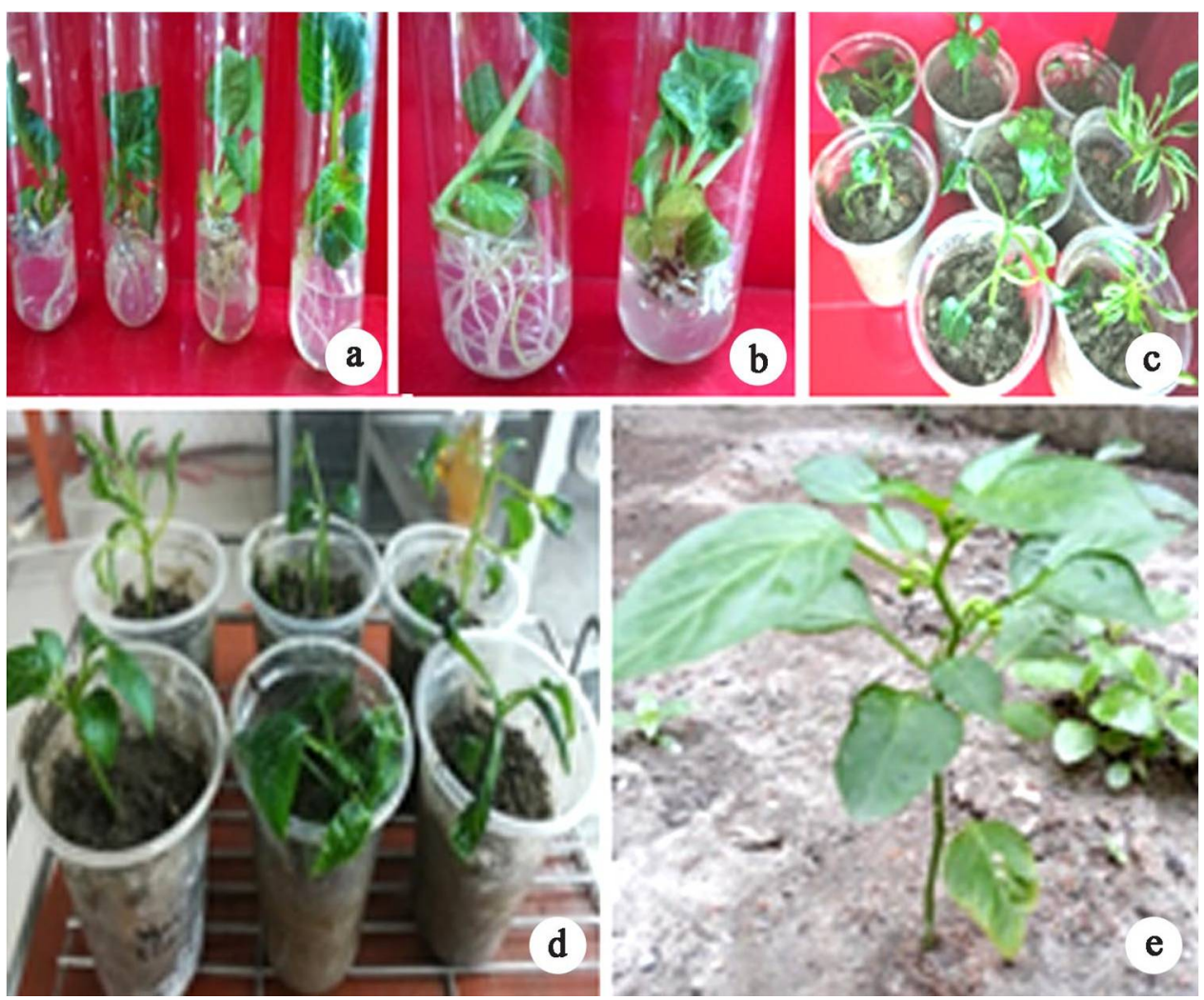

Fig. 3. Formation of roots and transplantation of plantlets of C. annuum from in vitro regenerated shoots.

(a) Formation of roots on MS with $0.5 \mathrm{mg} / \mathrm{IBA}$ of red variety; (b) same as Fig. (a) but in yellow variety, (c) transplantation of red variety in plastic pot; (d) acclimatization of plantlets of yellow variety; (e) mature plants of red variety in soil.

Occasionally a small amount callus was produced at the base of shoots (Fig. 11). Arous et al. (2001) observed maximum regeneration in C. annuum with $5.0 \mathrm{mg} / \mathrm{BAP}$ and 1.0 mg/ NAA using cotyledon explants. Otroshy et al. (2011) obtained best results on MS containing BAP $(6.0 \mathrm{mg} \Lambda)$ and IBA $(1.0 \mathrm{mg} /)$ from cotyledon explants of $C$. annuum. Swamy et al. (2014) also obtained a satisfactory result when they cultured cotyledon in MS with BAP $(2.0 \mathrm{mg} \Lambda)$ and NAA $(0.5 \mathrm{mg} \Lambda)$ with an average shoots/explant of $3.6 \mathrm{in}$ yellow variety. Further they reported an average of 6.3 mean number of shoots/expants the same media combination, in red variety of Capsicum. Present study supports the observation of Swamy et al. (2014), where the red variety showed a better regeneration response than the yellow type. 
For induction and development of roots, freshly prepared PGRs free MS and MS with different concentrations of IBA $(0.25-1.0 \mathrm{mg} /)$ were used. It was observed that roots initiated in PGR-free MS and MS with all the concentrations of IBA from the two varieties of Capsicum (Fig. 2). In the present study, the best response towards root induction was observed on MS with IBA $(0.5 \mathrm{mg} /)$ in two bell pepper varieties (Fig. 3 a,b). In contrast, Pishbin et al. (2014) and Hasnat et al.(2007) used half of the MS basal medium containing $1 \mathrm{mg} / \mathrm{IBA}$. Alongside, Renfiyeni et al. (2017) found best medium for root induction, and elongation was WPM (Woody Plant Medium supplemented with 0.4 mg/ NAA. Furthermore, Song et al. (2010) used MS without PGRs for rooting C. annuum 'Hivita Red' and 'Hivita Yellow' variety. The rate of survibality of the transplanted plantlets was found to be $85 \%$ in red variety (Fig. 3c) as against $55 \%$ in yellow variety (Fig. 3d).The plantlets matured in $2-2.5$ months (Fig. 3e).

The present study demonstrated a simple, efficient and reproducible direct shoot regeneration system for two locally available capsicum variety using cotyledonary node and cotyledonary leaf explants. Cotyledonary leaf was found more competent towards shoot induction. This system could be recommended for future gene transformation protocols with useful candidate genes.

\section{References}

Arous S, Boussaid M and Marrakchi M (2001) Plant regeneration from zygotic embryo hypocotyls of Tunisian chili (Capsicum annuum L.). J. Appl. Hortic. 3(1):17-22.

Ashrafuzzaman M, Hossain M, Razi M and Haque MS (2009) Regeneration potential of seedling explants of chilli (Capsicum annuum). Afr. J. Biotechnol. 8(4): 591-596.

BhutiaKL, Meetei NGT and Khanna VK (2016) In vitro regeneration of Dalle Khursani, an important Chilli cultivar of Sikkim, using various explants.Agrotechnology5: 142.

Borychowski A, Szczytt KN and Jedraszko M (2002) Plant regeneration from Sweet Pepper (Capsicum annuum L.) Hypocotyl explants. Acta Physiol. Plant. 24(3): 257-264

Dabauza M and Pena L (2001) High efficiency organogenesis in sweet pepper(Capsicum annuиm L.) tissue from different seedling explants. Plant Growth Regul. 33: 221-229.

Khan S, Banu TA, Akter S, Goswami B, Islam M, Hani U and Habib A (2018) In vitro regeneration protocol of Rauvolfia serpentina L. Bangladesh J. Sci. Ind. Res. 53(2): 133-138.

Kumar OA, Tata SS and Rupavathi T (2011) Multiple shoot induction and plant regeneration from nodal explants of Chili Peppers (Capsicum annuum L). Asian J. Expt. Biol. Sci. 2 (3): 517-520

Hegde V, Partap PS and Yadav RC (2017) Plant regeneration from hypocotyl explants in Capsicum (Capsicum annuum L.). Int. J. Curr. Microbiol. Appl. Sci. 6(7): 545-557

Halim GMA and Islam MS (2013) Performance of sweet pepper under protective structure in Gazipur of Bangladesh. Int. J. Environ. 1(1): 1-8.

HasnatR,Abbasi NA, Ahmed T and Hafiz IA (2007) Induction and Regeneration of Hypocotyl drive calli in hot chili (Capsicum frustencens L.) varieties. Pak. J. Bot. 39: 1787-1795.

Hill K and Schaller GE (2013) Enhancing plant regeneration in tissue culture: A molecular approach through manipulation of cytokinin sensitivity. Plant Signal. Behav. 8(10): e25709 
Mahmud N, Chakma R, Ahmed N, Zaman M and Hossain A (2017) Effect of sowing date on quality seed production of sweet pepper in Bangladesh. Progress. Agric. 28(3): 216-221.

Phillips GC and Hubstenberger JF (1985) Organogenesis in pepper tissue cultures. Plant Cell, Tissue Organ Cult.4: 261-269.

Pishbin N, Mousavi A, Kalatejari S, Shariatpanahi M and Jahromi B (2014) The effect of plant growth regulators and different types of explants on in vitro regeneration of sweet pepper (Capsicum annuum L.). Int. J. Biol. Sci. 5: 139-146.

Orlinska M and Nowaczyk P (2015) In vitro plant regeneration of 4 Capsicum spp. genotypes using different explant types. Turk. J. Biol. 39: 60-68

Raj RP, Glint VD and Babu KN (2015) In vitro plant regeneration in Capsicum chinense Jacq. (Naga Chili). J. Appl. Biol. 3(1): 30-33.

Renfiyeni, Syukriani L,Asben A and Jamsari A (2017) Optimal media for in vitro regeneration of two local genotypes of chili pepper (Capsicum annuum L.) from west sumatera. Int. J. Adv. Sci. Eng. Inf. Technol. 7(3): 904-909.

Saleh BK, Omer A and Teweldemedhin B (2018) Medicinal uses and health benefits of chili pepper (Capsicum spp.). MOJ Food Processing \&Technology 6(4): 325-328.

Sanatombi K and Sharma GJ (2007) Micropropagation of Capsicum annuum L.Not Bot Horti Agrobot. Cluj Napoca. 35(1): 57-64

Saha SR and Salam MA (2004) Modern techniques of sweet pepper cultivation. A booklet published by plant physiology section, HRC, BARI, Gazipur.

Song JY, SivanesanI, An CG and Jeong BR (2010) Adventitious shoot regeneration from leaf explants of miniature paprika (Capsicum annuum) 'Hivita Red' and 'Hivita Yellow'. Afr. J. Biotechnol. 9(19): 2768-2773.

Swamy S, Krupakar A and Koshy EP (2014) Direct regeneration protocols of five Capsicum annuum L. varieties. Afr. J. Biotechnol. 13(2): 307-312.

Venkatain P, Cristopher T and Subhash K (2001) Plant regeneration and Agrobacterium mediated genetic transformation in four Capsicum species. Capsicum and Eggplant newsletters. 20: 68-71. 